\title{
What's in a Name? The Experience of the Other in Online Classrooms
}

Catherine Adams, University of Alberta, Edmonton, Canada

Email: cathy.adams@ualberta.ca

A proper name changes in quality in reference to the first impressions we have in meeting someone for the first time. There is good reason why first impressions are important for they are the first indexical way we encounter the person named. (Weber, 2008, p. 348)

Our continuing use of names rather than numbers should be considered a passing stage.

(Flusser, 2011, p. 26)

[O] ur imagined identities never fully match that bundle of behaviors which comport themselves under our name.

(Pettman, 2006, p.xi)

\section{Abstract}

Educational research has explored the potentials and problems inherent in student anonymity and pseudonymity in virtual learning environments. But few studies have attended to onymity, that is, the use of ones own and others given names in online courses. In part, this lack of attention is due to the taken-for-granted nature of using our names in everyday, "face-to-face" classrooms as well as in online learning situations. This research explores the experiential significance of student names in online classrooms. Specifically, the paper reports on one relational thematic that surfaced in a phenomenological study investigating experiences of teaching and learning online.

\section{Introduction}

How far we have travelled from the peripatetic pedagogue with child-at-hand to today's Massive Open Online Courses! The idyllic vision of teacher and student conversing on a log now finds its postmodern equivalent in teacher and students typing responses to one another, sometimes late into the night by the light of a laptop or mobile device, seldom in a shared timeframe. "Face-toface" pedagogical relations are giving way to and blending with "face-to-screen," an uncoupling and rendering fluid of the time- and space-bound rhythms and structures that have defined schooling for the past century. The locally situated, relational intertwinings and prereflective immediacies of the lived classroom are being quietly abandoned for more "promising," unfettered and reflective virtual territories. Yet how are these often subtle but sometimes 
dramatic shifts felt in the everyday world of teaching and learning? In this paper, I explore one aspect of pedagogical relation that surfaced in a larger phenomenological study investigating teaching and learning in Learning Management Systems, specifically, the significance of names.

I begin with an overview of the research on names, pseudonyms and anonymity in online learning spaces. I then describe the human science methodology employed in this study: van Manen's (2014) "phenomenology of practice." The balance of the paper maintains a modest cadence: anecdote-reflection, anecdote-reflection. Each anecdote derives from an experiential moment recollected in the context of research interviews conducted with twenty online instructors and twenty students at two different post-secondary institutions. Following each anecdote or lived experience description, I reflect phenomenologically on the significance of the prereflectively apprehended moment. This simple prereflective-reflective rhythm mimics the main methodological gestures of this kind of research: a wondering, "perpetual beginner" reawakening to the lifeworld via recalling the primordial sphere of our everyday lives; this is followed by a disciplined reflective analysis of the "autonomous, lawful" (Crowell, 2011, p. 15) meaning-structures evidenced by raw, descriptive phenomenological datum, literally, the "(thing) given." Phenomenology's reflective grasp attempts to gain a more originary access to prereflective phenomena, "where meanings originate, well up, percolate through the porous membranes of past sedimentations (memories, habits, cultural and personal styles) - then infuse, infect, touch, and stir us, and exercise a (trans)formative affect" (van Manen, 2013, para. 3). Finally, I offer some normative considerations regarding the significance of this research for blended and online teaching.

\section{Anonymity, pseudonymity and onymity in online learning spaces}

One of the more unusual affordances of information and communication technologies is the ability to (temporarily) uncouple our given name from our person. This may be accomplished via the faceless mask of anonymity, the veil of an avatar or pseudonym, or the randomness of an assigned number. Much has been written on the significance of anonymity in online social spaces as well as its potentials and pitfalls for learning. Early on, Turkle (1995) made a compelling argument for the therapeutic value of constructing an avatar identity online, while Dibbell's (1993) "A rape in cyberspace" cast a more cautionary pall on anonymity's pathological possibilities. Marx (1999) situates the question of names and modern communication technologies within a conceptual landscape of anonymity, surveillance and identifiability. He suggests multiple rationales for anonymity - including facilitating information flow; encouraging experimentation and risk-taking; enhancing rituals, games, play and celebrations; protecting one's time, space and person; protecting reputation and assets; avoiding persecution; protecting personhood-as well as for identifiability which serves in aiding accountability; judging reputation; paying dues or receiving just deserts; determining eligibility; aiding in relationship building and social orientation. As rudimentary poles on a personal identification continuum, anonymity and anomity (identifiability) delineate a wide range of social, legal and ethical considerations and concerns regarding the use of digital communications and social media.

Online teaching and learning researchers have long experimented with the affordances of anonymity and pseudonymity. For example, Chester and Gwynne (1998), in an online course on "Personal Identity and Community in Cyberspace" discovered the "delights" as well as the "dangers" of pseudonymity. On the one hand, the use of aliases appeared to give students more control over revealing personal information, and tended to neutralize possible effects of gender 
and cultural bias; on the other hand, the anonymity of an alias opened the more likely occurrence of "negative disinhibited behavior" such as flaming. More recently, Miyazoe and Anderson (2011) explored the effects of anonymity in an English Language Learning (ELL) blended environment. Students, who met one another regularly in a face-to-face class, were instructed to choose a pseudonym for writing in the Moodle-based forums and blogs. Among the three blended classes studied, many students chose gender-free pseudonyms. Miyazoe and Anderson concluded that pseudonymity represented a nuanced form of anonymity in this context. Rather than providing opportunity to play with a new identity, pseudonyms served students in deindividualizing themselves (Connolly, 1990; Lu \& Bol, 2007) while still maintaining a sense of identity.

Using quasi-experimental research design, $\mathrm{Yu}$ and $\mathrm{Wu}$ (2011) examined the effects of four different "identity revelation modes"—real-name (identifiable), nickname (less identifiable assigned pseudonym), anonymous (not identifiable), and dynamic (student chooses among other three identity revelation modes) — on perceptions of others feedback in online peer assessment. Students who were allowed to self-select their identity mode and those assigned to the real name group tended to view their assessors more favorably than did those in the nickname and anonymous groups. However, the study detected no variation in the perception of the learning climate or in the learning activity between the four groups. Anwar and Greer (2012) developed an "identity management" system to assist students negotiating the calculus of trust and privacy necessary for learning in online learning environments.

Heisler and Crabill (2006) applied Uncertainty Reduction Theory (URT) to shed light on how 300 undergraduate students constructed perceptions of others based on email username. URT was developed by Berger and Calabrese (1975) to predict strategies used during initial face-to-face encounters. For this study, six fictional pseudonyms were generated and paired with a common Internet domain address. Results suggested that users employed the pseudonym to gather initial information about the individual including biological sex (74\%), race (56\%), and age $(65 \%)$. Students found creative user names (i.e., "stinkybug") significantly more revealing than alphanumeric codes (i.e., "ai4773"). (One can imagine a similar result with vanity plates verses regular license plates.) Based on their findings, the authors suggested that pseudonyms exist on an "information continuum," some names revealing more information than others. A similar observation was made by Steinkuehler and Williams (2006) about avatars in the context of their research on massively multiplayer online games (MMOs):

Avatars bear no discernable relationship to one's offline identity, unless one chooses to render one's own character so identifiable, for example, by using one's given name instead of a pseudonym (a rare practice) or sharing personal information about one's offline personae with others within the game. This anonymity provides a safe haven beyond the reach of work and home that allows individuals to engage with others socially without entangling obligations and repercussions; it is the so-called "magic circle" of the game. (p. 891)

Finally, Francis and Moisey (2012) studied the use of identification codes rather than names in an online, Moodle-based graduate course. Some students reported that the codes were impersonal and presented a barrier to communication. Nonetheless, Francis and Moisey reported that students in the class "did get to know one another," and that in some instances addressed one another by their code name (e.g. "LaraCe3"). Citing the work of Sfard and Prusak (2005), they 
suggested that identification codes acted as "designated identities" that over time appeared to become "actual identities" in the online environment.

Educational research has continued to explore the value anonymity and pseudonymity to learning, but few studies have explicitly attended to onymity, the experiential significance of using ones own and others given or proper names in online courses. In part, this lack of attention is due to the taken-for-granted nature of our names in everyday, "face-to-face" life. Online learning worlds have afforded, in some instances, the unusual possibility for students to be without a name for all or part of a course, and to temporarily construct and experiment freely with a new identity. A phenomenology of names-where one's name in the everyday, "real" world is contiguous with the online, "virtual" teaching and learning world - may give us a meaningful glimpse into this under researched but more usual experience of learning together online.

\section{Phenomenology of practice}

Phenomenology attends to the primordial stream of the lived "now" as it is given in everyday life, before the living moment may be theorized, conceptualized or otherwise reflected upon. The phenomenologist's prehension of the lived "now" always arrives too late; like the Orphean turn to his beloved Eurydice on her emergence from the underworld (van Manen \& Adams, 2009), the researcher may at best glimpse his or her phenomenon on its swift retreat back into the dark indeterminacy of the already past. In this sense, phenomenology is always an unfinished project; it is also why Merleau-Ponty declares the completion of phenomenology's central method, the "reduction," an assured impossibility (2012, p. xxvi). Yet despite its paradoxical nature, the reduction is nonetheless undertaken since unique insights may be gleaned in this momentary, wakeful glance back "to the things themselves!" (Heidegger 1962, p. 50). While accepting the ephemeral nature of the lifeworld, the human scientist strives to maintain fidelity to the prereflective phenomenon-as-given. In qualitative research practice, this always-too-late backward turn to lived experience is accomplished in part through gathering an ample collection of descriptive, retrospective accounts - remembered everyday moments and recollected occurrences - from those who have lived the phenomenon under study.

Phenomenology of practice, developed specifically for studying pedagogical environments in situ (van Manen, 1997), is especially adept at uncovering and fostering practical insights, communicative thoughtfulness and ethical sensitivities in professional teaching practice. The approach employs a variety of human science methods (e.g. written self protocols, field journals, participant interviews) and analytic techniques (e.g. thematic, guided existential, and eidetic reflection) to identify and explore variant and invariant meaning aspects of the phenomenon (van Manen, 2014). For example, in the phenomenological interview, the researcher prepares the participant to recover specific moments experienced in the past by asking questions honed to the situated nature of everyday life and oriented to the phenomenon of interest. In this way,

Little by little [a recollection] comes into view like a condensing cloud; from the virtual state it passes to the actual; and as its outlines become more distinct and its surfaces take on colour, it tends to imitate perception. But it remains attached to the past by its deepest roots, and if, when once realized, it did not retain something of its original virtuality, if 
being a present state, it were not also something which stands out distinct from the present, we should never know it as a memory. (Bergson, 1988, p. 171)

A participant's description of a recollected moment is never a "pure vector of recall" (Pettman, 2006, p. 45) unsullied by time, distance, and the limits of language and vagaries of memory. Nonetheless, such a "virtual" recollection or lived experience description (LED) "remains attached to the past by its deepest roots" (p. 45). Like Proust's madeleine, an LED has the potential to (re)evoke aspects of a remembered phenomenon in its original, lived sensibilities. Once a substantial body of LEDs has been gathered, each lived experience description is submitted to a variety of analytic techniques in an effort to gain a more originary access to the phenomenon as it is lived. For example, the researcher may compare an LED to the lived dimensions of other teaching and learning situations, or explore it thematically, as well as across key existential dimensions. In this way, a phenomenology of practice may attend to and examine how Learning Management Systems sponsor and provide for modes of teaching and learning that are inevitably embodied and situated in particular temporal, spatial, material, and relational contexts.

\section{Names without faces and the enigma of the other}

Reflecting back on a recent online course, a university student recalls,

In the very beginning the others were just a list of names, names that did not mean anything to me. ${ }^{l}$ (Online student)

We might construct a similar scenario for a student in a face-to-face class: "in the beginning, the others were just a sea of faces, faces that did not mean anything to me." But, can we really compare the online student's first reading of the names of fellow classmates with the situated event of the first day of class - a lively gathering of unfamiliar faces and voices, shuffling chairs and desks, books, pens and papers? Perhaps the experience is more akin to the teacher who, before meeting her students on the first day of class, glances down the class roster, and wonders: Is Jamie a boy or a girl? Does Joseph go by Joe? She may even rehearse each name out loud, pausing to practice the unusual ones. In one sense, each name appears to the teacher as a mere placeholder for an unknown student. The teacher has not yet met her students, so the list is merely a list of names: there is no relational ground or appeal. But in another sense, each name has already found early pedagogical home on her tongue. The speaking aloud of each name is one of many possible first teacherly gestures. The teacher reading or mouthing the names to herself anticipates her responsibility to each one spoken now and in the future: to be able to say the student's name correctly in class, to know that this or that student belongs to her for the duration of the course. The online student, however, knows no such pedagogic responsibility. Moreover, online, there is seldom call for the spoken word. Each name is read only as text: it is rarely if ever uttered out loud.

But still we must wonder, what does a student really see when they first encounter the names of their fellow students online? The online class itself - the course materials to be read, watched, listened to or explored, the discussions to be had, relationships to be struck, activities to be participated in, papers and examinations to be written-is still an unknown world, one that may be anticipated with excitement or trepidation, hope or uncertainty, desire or worry. The 
class roster also appears as an unknown world, a list of infinite possibilities yet to unfold. Those named are still strangers, indeterminate Others. Yet, like Levinas' ringing doorbell (Alford, 2002; Levinas, 1965/1996), each name on the roll also issues a distant call to its reader in those first moments, even though neither teacher nor students have yet opened the door to reveal who is there. In the epitaph to his essay "Enigma and Phenomenon", Levinas quotes a passage from the play, The Bald Prima Donna:

In short, we still do not know if, when someone rings

The doorbell, there is someone there or not ...

(Ionesco, in Levinas 1965/1996, p. 66)

In the play, these lines are spoken near the end of a protracted argument between husband and wife, in the wake of the wife answering the ringing doorbell only to discover, over and over again, that no one is there. At last the husband goes to the door, and the local fire chief is standing on the step. For Levinas, this passage expresses the enigma of the Other, the one who, as interruption, is both there and not there. When the doorbell rings, even before I open the door, I have already found a relation to the one calling, 'a relation without relation', whether someone is ultimately there or not. Just so, each name on the class roster is inevitably read and heard as a trace of the undetermined Other, the one who has not yet appeared, yet has nonetheless made themselves known as an unknown.

Reading the list of student names for the first time, neither teacher nor online student have glimpse of the person, the who, the "inward force of identity" (Weber, 2008) that each name identifies and names. To declare "In the beginning, the others were just a list of names, names that did not mean anything to me" acknowledges that I am not familiar with the people on this list; each name appears to me as a stranger. Yes, I have a modicum of propositional knowledge of each person-I know (savoir), for example, that someone named Sasha Smith is in my class; but I have no acquaintance knowledge of this individual, i.e. I do not know (connaître) who Sasha Smith is. In encountering the name "Sasha Smith" for the first time, no presence is called into being, no unique "relational quality...that pertains between this person and me" is evoked (van Manen, 2014, p. 21). Sasha Smith, it seems, is but two words gesturing toward a person with whom I am not yet familiar.

As the online student tells us, in the beginning, the names of others meant nothing to him. Yet is this true? In those first moments of perusing the names, those in the class are no longer nameless. Indeed, as each name is read, if only in the most glancing sense, a unique aspect of the one named is announced and apprehended by me. The physiognomy of each name-its syllabic contours and prosodic rhythm, the softness or hardness of its vowels and consonants, its difficulty on the tongue, its cultural heritage and etymological roots, its formality, foreignness or familiarity-whispers a secret or two to me about its bearer. Here Barthes reminds us that proper names have an erotic aspect: "like voices, like odors, [names] would be the terms of a languor: desire and death: "the last sigh which remains of things"" (1994, p. 1). Uttering the name "Sasha" to oneself, ones lips remain gently parted, its double sibilance hypnotically soft against the ear. Too, as Tschaepe discerns, one's "name is both a liberation through identity and a powerful order of limitation through its physiological and referential bondage" (2003, p. 68). Is Sasha a man or a woman? Where is he or she from? Is Sasha short for Alexander or Alexandra? Maybe this person is of Russian or Slavic descent? While perhaps few of us hail from cultures where one's name "is linked to the very being of the [one] named....in its most intimate nature" 
(Gusdorf, 1962, p. 12), our name nonetheless betrays something about us. More so than the distant anonymous ring of Levinas' doorbell, the gestural peal of each name on the screen is always already "pregnant with a meaning" (Merleau-Ponty, 1960/1964, p. 88), quietly calling forth a singularity and intoning significance poignantly unique to the individual to whom it belongs.

\section{Coming to a sense of the who-ness of the named other}

In the very beginning the others were just a list of names, names that did not mean anything to me...

The student continues:

...But now, several months later, I have come to know these names: like a coming into being of something unique that is difficult to put into words. For example, I still do not know who Sasha is-I have not met her-and yet I have a sense of who she is. I remember reading her response to something that I had written in the discussion area early on. She seemed to respond to me with words that touched so deeply what I was trying to say-I felt stirred by this person who could relate to my thoughts. So, in this online class something came about, something grew, that was truly special. (Online student)

Sasha remains an enigma, an unknown "who." Yet, the student now has "a sense of who Sasha is." He has not met the "who" that is Sasha in the face-to-face nakedness of his or her eyes; nonetheless the online student has come to know (connaitre) Sasha. How has this happened? Clearly the passing of time together in this shared, asynchronous learning space has contributed to this difference. But more particularly, it is in the reading and writing, in the responding and co-responding in the textual space of the online discussion forums, where the student comes to know the other. Language is a proximal sensibility. Through words, we draw near to (and sometimes away from) the other, and the other draws near to (or away from) us. We find relation, literally, we are borne back $\left(\right.$ re-latus $\left.^{2}\right)$ to the other through our listening and our saying. "Language, contact," says Levinas (1987), "is the obsession of an I 'beset' by the others" (p. 123).

Reading the words composed by the named-other, in the midst of an online classroom space, I find myself faced. I am called to respond, to take up my responsibility, my relation without relation to the unknown Other, the one named. Even in the complete absence of the immediacy of the living, breathing corporality of gesture and carriage, and bereft of the physiognomy of face and eye contact, online, the other, the named-one appears and makes an appeal to me. Such a call may be felt in a particular turn of phrase, in the unexpected coresponsiveness of another's words to my words, in the melodic, prosodic and tonal fingerprints of the text. Reading the posts of another, I am prereflectively touched by and infected with the textual voice of the one who composed these particular words, phrases, thoughts and reflections. A doorbell's ring announces someone at the door, a someone who may or may not be there. Online, each authored text issues another melody of meaning; an acoustic "halo of identity" (Tschaepe, 2003) that gathers the flesh of significance over time. Each new post imbricates another textual note, a resonant chord in an unfinished composition entitled "Sasha." Sasha's presence is evoked through words that "touch so deeply" what the student was trying to say. Yet 
Sasha is not there. Sasha appears as an absent or invisible presence who can nonetheless touch and stir the other. No one is there, only evocations and silent whisperings in the night, by the soft glow of a laptop screen.

\section{Being named draws one into a sphere of closeness and responsibility}

After the second writing exercise, we were asked to give feedback to another student. I was paired with Qiang. When I wrote to him, I felt much more self-conscious and responsible for what I wrote than usual. Later, someone else in the class mentioned me regarding something I had written. I felt warmed to him and compelled to respond. Like with Qiang, I read his post over multiple times before I responded. I wanted to get it right. After that, I paid more attention to what he wrote. The mere fact of being singled out by name changed things for me. (Online student)

The teacher pairs an online student with another, and it awakens in him a sense of responsibility for his classmate. This same student, in finding himself mentioned by a fellow student in the context of an online forum discussion, is drawn into a more intimate, attentive relational sphere with this individual. Such moments remind us that when we are addressed by name-whether online or offline, we feel singled out in our personhood. We are prereflectively addressed and called to respond:

When someone calls us by our name (especially when this someone is a significant person), then we may feel addressed in our singularity. Calling a person by his or her first name may create a sense of intimacy and trust. (van Manen, McClelland, \& Plihal 2007, p. 85)

Yet what happens in this moment when we are called by name? "To name" someone or something, says Gusdorf (1962), "is to call into existence" (p. 38). When the student encounters his name in another student's post, he finds himself warmed and "compelled to respond." Merleau-Ponty (1945/1962) situates the intelligibility of language and more specifically naming at the resonant center of our sensible body:

My body is the fabric into which all objects are woven...[M]y body is not only an object among all other objects, a nexus of sensible qualities among others, but an object which is sensitive to all the rest, which reverberates to all sounds, vibrates to all colors, and provides words with their primordial significance through the way in which it receives them. It is not a matter of reducing the significance of the word "warm" to sensations of warmth by empiricist standards. For the warmth which I feel when I read the word "warm" is not an actual warmth. It is simply my body which prepares itself for heat and which, so to speak, roughs out its outline. (p. 273, 275)

When I read my name, my body has already prepared a space for my "I", my who-ness. My prereflective being is halted in its intentional track and "roughs out an outline" of "me". Such a direct address to selfhood (re)founds and locates my subjectivity-my sense of who-I-am-nessand (re)constitutes a relation with the one who calls me. Too, I may have more than one name, 
and each will evoke a different version of me-ness. The names "Cath" or "Mom" or "Dr. Adams" are all me, but each calls forth and invites a particular relational sphere. Each name summons a somewhat different sense of who I am in the world, each with its own responsibilities, cares and joys. Too, by whom and the manner in which I am addressed evokes different tones and concernful sensibilities. Naming is not only a way to indicate or point to the other and call them present; naming declares and constitutes the relationship with the other.

Too, there are times when we hope we are not called on by name. The student who neglected to do her homework may keep her head bowed and pray the teacher does not find her eyes or call on her by name. In the absence of eye contact, the teacher may still draw the student to the centre of attention by saying her name. If the teacher does call on the student, the child or youth may feel suddenly in the spotlight and be faced with admitting the truth of the situation, guessing an answer, or simply remaining painfully silent. Regardless, to be named is to be called to one's responsibility. Most especially in a pedagogical context, being singled out by name is also a normative invocation: my name is heard as a plea to be not simply "me", but the one I "ought to be." As a student, my name calls forth both "me" and "not-me"; the centripetal, pathic sense of who I am in my everyday is uprooted and unfurled-gently, unexpectedly, or sometimes forcibly_ in a centrifugal demand to be more.

\section{The other appears as a "browsing" nonappearance, an incursion into the online but still preparatory and private curricular space}

The day before classes begin, an instructor is busily adding a few last minute touches to her online course. She decides to go for a walk, and on her return she logs back into the class LMS. Then, as the instructor describes it,

I stop short. The "Who's Online" indicator on the left hand side of the screen shows there are students browsing around my course. I feel like I've been invaded! I spent hours and hours working on this course; so far, it has been my private domain. But now it is taking on a life of its own, independent of me. Suddenly, I feel reluctant to make those changes; it seems the module that I created is no longer mine alone to control. (Online instructor)

The instructor is arrested in her online tracks. "Browsing students" have unexpectedly appeared on the scene, a day early, their presence announced by a bracketed number beneath the "Who's Online" indicator on the teacher's Blackboard LMS dashboard. The teacher encounters these early arrivers as an incursion: over-enthusiastic invaders intruding on and disrupting the stable quietude of her preparatory domain. Then, like a gracious host confronted with over-early guests, the teacher foregoes her preparations and settles in to welcoming. This unexpected event also marks the advent of something lively, autonomous, and wholly other: the space of the LMS has taken on "a life of its own," a life that immediately exceeds and overflows the significance of the teacher alone. The online class has begun.

The Other, as Levinas shows, is not a phenomenon at all, but "an interruption or disturbance" of our world (Peperzak, Critchley \& Bernascone, 1996, commentary on Levinas' "Enigma and Phenomenon", p. 65). We are given access, not to the Other but rather "to the Other's nonappearance." Such nonappearance may be poignantly felt in the context of communication technologies. As I read an email from a colleague, her voice and person are 
imperceptibly re-evoked for me as I consider the request. Responding to the email, she is there before me, and yet she is not there at all. I answer the telephone, and the voice of a missed loved one, who is now living far away, caresses my ear. Yet he himself does not materialize before me. On the phone, the distance between my loved one and me is momentarily bridged yet remains maddeningly untraversable. But admittedly, even if he was standing before me in this very moment, an insurmountable distance always lives between me and my beloved, the Other. So what difference does a technology make?

Technology-mediated conversations - whether they transpire synchronously or asynchronously, across the hall or across the ocean - are real, palpable and have an effect. When teacher notices that the "Who's Online" indicator displays an integer greater than one, she is stopped in her tracks by "students browsing around." Like Levinas' doorbell, the Other -if they are there at all - necessarily remains an enigma on the other side of the door, beyond my sensible, immediate grasp. Like one's hand reaching and opening in anticipation of the doorknob, the teacher too tends toward and opens her teacherly being to welcome her students, the early arrivals who are already off course!

Such technology-mediated "nonappearances" betray the vexing play of presence and absence, the "here yet not-here"-ness that is rooted in our deeply embodied sense of the proximal immediacy of face-to-face. A telephone grants me the semblance of immediate access to my loved one's voice, but deprives me of the near embrace of their substantive, corporeal body. An email or text withholds from me the nuance of the voice, countenance and bodily presence of my colleague, but grants the meaningfulness of their words, their style of writing and way of relating. Rather, all linger as punctive traces but bereft of contemporaneous immediacy. The "Who's Online" numeric indicator ruptures the teacher's preparatory sphere with an imagination of "students browsing around," yet no meaningful "whos" have yet appeared before her.

While Levinas's interruptive nonappearance points up a more radical relation with the Other, we may also notice that medial technologies intensify and uniquely complicate our paradoxical sense of the other, one that philosopher Simone Weil evokes succinctly in her recuperation of Plato's term, the metaxu (Mersch, 2010). Metaxu is Greek for "in-between-ness," and in Latin translates as "medium." Weil describes the metaxu as that which both separates and connects us. She illustrates with a little story: Two prisoners are housed in adjoining cells, and in order to communicate with one another, they use the wall that separates them to tap messages. The wall, like all media technology, is metaxu: it is an intermediary, a medium of communication, an in-between place that stands between us while simultaneously provides a means to correspond. It is an interface.

Such interfacial spaces are necessarily "between" places, neither one nor the other, but a "third". Media theorist Dieter Mersch (2010) names this third place, the diaphanos. Diaphanos, another Greek word, but this time from Aristotle, is that which permits us to see through, as we might see through a very fine, translucent veil of silk:

Phanis ... refers to phos, the light and phaino or phenomenon which originally means apparition, however an apparition which shines in itself and is met by the gaze of a beholder which is also active and hence always already intertwined with illusion and deception. (n.p.)

Understanding the medial interface as a diaphanos, we may begin to discern digital media technologies as very fine, diaphanous but deceptive overlays or illusory horizons that encroach 
upon and shade our lifeworld. In as much as new media is diaphanous, we may both look at it as well as through it. That is, we more and more perceive and apprehend our world through new media's illusory veil of translucence or "see-throughed-ness." The transparent but deceptive quality of this sight is given to us via the unique lens afforded by a given media technology's materiality: its textures and hues, networks and pathways, algorithms and vocabularies. Returning to Simone Weil's anecdote: clearly the prisoners cannot see through the wall as we might see through a sheer veil. Yet, when one hears the knock of the other on the wall, as with the "Who's Online" indicator, the other indeed appears "through" the wall, or the diaphanous interfacial software fabric of the Learning Management System.

Yet is this a correct way of speaking about the significance of the "Who's Online" indicator in an LMS? The teacher describes the space of the LMS as her own "private domain," which unexpectedly takes on an autonomous life of its own. The "Who's Online" indicator is not the Levinasean "epiphany of the face", but rather an incursive event given by number, not name. Nonetheless, the tally of students currently online registers as a demand. The count counts. We might imagine a teacher, having returned from a walk, opening her classroom door expecting the familiar stillness of her preparatory solitude, and instead encountering a group of strangers milling about, their backs turned and faces strangely obscured from view. But this is overstating the situation. The online teacher, halted by an indicator signifying that her "private domain" is now alive with students, must simply shift gears. Relinquishing her not-quite-finished "module," she turns to tend to the gathering fold of students. The students' non-appearance as an incursion calls the teacher to teach, to transition from constructing her curriculum-as-planned to joining her students in the curricular sphere opened at the hand of the Learning Management System.

\section{Virtual world meets "real" world: Who is the "who" with whom we correspond online?}

About a year after teaching my first online class, one of the students contacted me. She invited me to drop by a face-to-face course on campus: most of the cohort would be attending. As the day approached, I found myself feeling very excited about this unique opportunity to meet most of my former "online" students in-person. I had come to know them all so well over our 4 months online together! Entering the classroom that day, full of anticipation, I looked around and suddenly realized I knew none of them. Whatever imaginations I had built up and held so dearly about each of them did not translate in person. Instead, I found myself in a room full of strange people who I had come to know and care about, but suddenly I didn't know them at all. (Online teacher)

A teacher is astonished that, despite developing a rich, rewarding set of teacherly relationships with her students online, in person, her class suddenly turned into a room full of strangers. Standing face-to-face before her former students, she does not recognize them. The teacher ventures a few tentative guesses: Are you Dan? Jacob? (No. No. I'm Philip.) You must be Jayne?! (No.) All, except for one of her attempts, turn out to be wrong. Embarrassed, she asks if they could go around the room and say their names out loud. As each name is spoken, the teacher strains, trying hopelessly to associate familiar - no, fondly remembered - names with decidedly unfamiliar people. Confounding matters is that Dan does not look at all like Dan, whose thoughtful reflections and beautiful writing she had come to greatly admire, and Jayne in person seems so much older and sterner than her sanguine, always gracious online self. How is it 
possible to come to know one's students apparently so well in an online class, yet fail to recognize them in person? With whom are we corresponding when we teach and learn online? In other words, who have we really come to know? Too, is the flesh-and-blood person standing before me really the "truer" re-presentation of that self?

Having met and conversed with a person face-to-face, stood in the midst of their gestures, the tone and timbre of their voice, their way of comporting themselves and of relating to others, subsequent online correspondence will necessarily be read against the horizon of this and future in-person encounters. Such is the so-called blended learning experience. The fleshy body is written back into the online text as it were, and too, the online text rewrites the face-to-face relational sphere. In the blended classroom, the other is experienced across multiple modalities: in the proximal presence of self-conscious bodies, in the immediacy of animated conversation, in pregnant or awkward silences, in the sharing of laughter and of glances and smiles; but also in the more reflective sphere of online text to text. But when a class has transpired exclusively online, no bodies are present to witness and grope for relation to the other, and thus no flesh-andblood rewriting may occur. In such a situation, the online, nominal self and the offline, embodied self remain strangely incommensurable. Online, without ever having met the "in-person" person, we have only a name to anchor and meaningfully gather his or her unique body of text, and compose a sense of personhood. Later attempts to rejoin a body of writing experienced only online to its in-the-flesh author may unexpectedly upset one's imagined or "virtual" understanding of the world.

Encountering a disruptive difference between authored text and the in-person person is hardly a $21^{\text {st }}$ century phenomenon; rather it derives from the ancient technai of language, orthography, and epistolary communication. In Edmond Rostand's Cyrano de Bergerac, for example, Roxane believes mistakenly that the handsome young Christian penned the letters that won her heart, and thus she unknowingly overlooks the large-nosed, flesh-and-blood Cyrano. Only many years later, upon hearing Cyrano reciting her beloved's farewell letter to her on his deathbed, does Roxane at last recognize the letter's true author. At this, she declares her love for Cyrano, but of course it comes too late. The tale suggests that the relationality of (romantic) love may find its truest weave in words: "Passion is a semiotic affair," declares Kaja Silverman (2000, p. 50). But it also seems that it is only in context of the mortal body that love may at last be reconciled. Yet we must wonder: with whom did Roxane originally fall in love? Was it with the eloquent but ephemeral writing of the unrequited Cyrano, or with the carnal presence of the "outwardly" beautiful Christian? Such questions highlight the artificially rendered but strikingly painful cleave between inside and outside, body and soul, tongue and text. Such epistolary-only love relationships are necessarily cast as tragedy: only when text and body are reunited in both the imagination and the immediate presence of the other, if only briefly, does the reciprocity of love find its ground. Yet the question remains: with whom did Roxane fall in love? And online, who is the Other with whom we correspond as teachers, and as students? 


\section{Conclusion}

Texts are a search for the Other...texts are outstretched arms trying, whether optimistically or in despair, to be taken up by another. This is what the gesture of writing is disposed to do.

(Flusser, 2011, pp. 39-40)

New media technologies have unpinned many of the implicit, taken-for-granted social norms that have governed our everyday lives to date. Our personal names, however arbitrarily chosen, also backdrop our lifeworld; they are intimately intertwined with our sense of identity. Just as our bodies always already give us our originary bearing and sense of place on this earth, so our names anchor and orient us in the world of language and human sociality. Our names establish that we are each a who, a singular somebody who belongs to the community of human beings. In an online classroom, this is no less so. When another addresses us by name, we are called in our person, as a unique individual. As a child, my name founded me as me; and the Other's name-your name-identifies and grounds you as you. In online learning spaces, each name similarly demarks a singular "halo of identity" (Tschaepe, 2003, p. 67), a denotation that gathers connotative significance for others over time and texts. Online, the student's name is like Levinas' doorbell, announcing an unknown arriver at the door, the one who is there but not there. To the teacher, it is simultaneously a call to responsibility, and to pedagogical relation.

In his "Is There a Body in This Class," Norm Friesen (2002) wrote that in virtual learning environments,

There is no "body" in this class to name or to "meet". There is only the person's name itself, a label without an object...There is no such experience of presence in an online, text-based forum. In front of the computer screen and the virtual space offered by the conferencing software, there are only names with absent owners. (pp. 225, 226).

True. Yet even as there is a "conspicuous absence of the body" (p. 226) in an online classroom, experientially, for both teacher and student, there is nonetheless a face behind every name, and behind every face, a singular, unique person. As Levinas reminds us, whether he or she is standing before us or is hidden behind a door, the other remains a perpetual enigma, an unknowable who.

Whether a course convenes in a face-to-face or online classroom, the language of pedagogy appears capable of eloquent, meaningful, relational speech. Online, it is the unique name of the teacher and of each student that serves to ground significance, and shelter relational sensibilities. Moreover, such meaningfulness is only possible against the background of belonging to an intelligible, flesh-and-blood human community. Without this sensible foundation in the ethically-bound lifeworlds of both teacher and student, learning online threatens retreat into the hopelessness of Narcissus and Echo. Narcissus asks, "Who's there?" to which Echo echoes, "Who's there?" In the end, Narcissus becomes lost in the beauty of his own screenic reflection, and a disembodied Echo finds herself a lone and distant voice in the otherwise silent wilderness. Yet Narcissus' enchantment also hints at our fundamental sense of solidarity with the larger world: "primary narcissism is more than autoeroticism; it engulfs the 'environment,' integrating the narcissistic ego [one's own body] with the objective world" (Marcuse in Pettman, 2012, p. 175). Texts' "outstretched arms" (Flusser, 2011, p. 40), authored by a named Other, 
carry the very real potential to interrupt, touch and occasionally break through the spell of Narcissus in virtual learning environments.

\section{Notes}

1. Italicized quotes represent material collected during interviews with university students and instructors and/or via solicited written experiential descriptions as part of a SSHRC-funded research project. All names are pseudonyms. Participant interviews adhered to the guidelines set by the Tri-Council Policy Statement: Ethical Conduct for Research Involving Humans.

2. re- "back, again" + latus "carried, borne" (used as suppletive past participle of ferre "to bear")

\section{References}

Alford, C. F. (2002). Levinas, the Frankfurt School, and psychoanalysis. Middletown, Connecticut: Wesleyan University Press.

Anwar, M. \& Greer, J. (2012). Facilitating trust in privacy-preserving e-learning environments. IEEE Transactions on Learning Technologies, 5(1), 62-73.

Barthes, R. (1994). Barthes by Barthes. (R. Howard, Trans.). Berkeley, CA: University of California Press.

Berger, C. R., \& Calabrese, R. J. (1975). Some explorations in initial interaction and beyond: Toward a developmental theory of interpersonal communication. Human Communication, 1, 99-112.

Chester, A. \& Gwynne, G. (1998). Online teaching: Encouraging collaboration through anonymity. Journal of Computer-Mediated Communication, 4(2). doi: 10.1111/j.10836101.1998.tb00096.x

Chester, A., \& Gwynne, G. (1998). Online teaching: Encouraging collaboration through anonymity. Journal of Computer-Mediated Communication, 4(2), 0-0.

Crowell, S. (2011). "Idealities of nature": Jan Patočka on reflection and the three movements of human life. In Jan Patočka and the Heritage of Phenomenology (pp. 7-22). Springer Netherlands.

Dibbell, J. (1993). A rape in cyberspace, or how an evil clown, a Haitian trickster spirit, two wizards, and a cast of dozens turned a database into a society. Village Voice, Dec. 21, 3642.

Flusser, V. (2011). Does Writing Have a Future? (N. A. Roth, Trans.). Minneapolis, MN: University of Minnesota Press.

Francis, K., \& Moisey, S. (2012). We are not numbers: The use of identification codes in online learning. Journal of Distance Education, 26(2).

Freeman, M. \& Bamford, A. (2004). Student choice of anonymity for learner identity in online learning discussion forums. International Journal on E-Learning, 3(3), 45-53. Available from http://www.editlib.org/p/4377/

Friesen, N. (1997). Is there a body in this class? In M. van Manen (Ed.), Writing in the dark: Phenomenological studies in interpretive inquiry (pp. 223-235). London, ON: Althouse Press. 
Friesen, N. (2011). The place of the classroom and the space of the screen: relational pedagogy and Internet technology. New York, NY: Peter Lang.

Gitelman, L. (1999). Scripts, grooves, and writing machines: representing technology in the Edison era. Stanford, CA: Stanford University Press.

Green, K. C. (14 Oct 2010). The 2010 campus computing report. Retrieved from http:/www.campuscomputing.net/sites/www.campuscomputing.net/files/GreenCampusComputing2010.pdf

Gusdorf, G. (1965). Speaking (la parole). Evanston, IL: Northwestern University Press.

Harman, G. (2007). The tetrad and phenomenology. Explorations in Media Ecology, 6(3), 189196.

Heidegger, M. 1962). Being and time (J. Macquarrie \& E. Robinson, Trans.). New York, NY: Harper \& Row Publishers

Heisler, J. M., \& Crabhill, S. L. (2006). Who are "stinkybug" and "Packerfan4"? Email pseudonyms and participants' perceptions of demography, productivity, and personality. Journal of Computer-Mediated Communication, 12(1), 114-135.

Ihde, D. (1983). Existential technics. Albany, NY: State University of New York Press.

Kazan, T.S. (2007). Braving the body: Embodiment and (cyber-) texts. In J. Lockard \& M. Pegrum (Eds.), Brave new classrooms: Democratic education and the Internet (pp. 251269). New York, NY: Peter Lang.

Ke, F., Chávez, A. F., Causarano, P. L., \& Causarano, A. (2011). Identity presence and knowledge building: Joint emergence in online learning environments? International Journal of Computer-Supported Collaborative Learning, 6(3), 349-370.

Levinas, E. (1965/1996). Enigma and phenomenon. In A. T. Peperzak, S. Critchley \& R. Bernascone (Eds.), Emmanual Levinas basic philosophical writings (pp. 65-77). Indianapolis, IN: Bloomington.

Marion, J-L. (1999). The other first philosophy and the question of givenness (J. L. Kosky, Trans.). Critical Inquiry, 25(4), 784-800.

Marx, G.T. (1999). What's in a name? Some reflections on the sociology of anonymity. The Information Society: An International Journal, 15(2), 99-112. doi: 10.1080/019722499128565.

McLuhan, M. (2003). Understanding me: Lectures and interviews (S. McLuhan \& D. Staines, Eds.). Toronto: McClelland \& Stewart.

Merleau-Ponty, M. (2012). Phenomenology of perception (D. A . Landes, Trans.). New York,NY: Routledge.

Merleau-Ponty, M. (1960/1964). Signs (R. C. McCleary, Trans.). Evanston, IL: Northwestern University Press.

Mersch, D. (2010). Beyond information theory and structural analysis. A new approach to the theory of mediation. Media Transatlantic Conference, Vancouver. Available at: http://www.mediatrans.ca/ 
Miller, V. (2012). A crisis of presence: On-line culture and being in the World. Space and Polity, 16(3), 265-285.

Miyazoe, T. \& Anderson, T. (2011). Anonymity in blended learning: Who would you like to be? Educational Technology \& Society, 14(2), 175-187.

Onstad, K. (6 November 2012). Hollywood and Botox: Is the face being erased in our culture? Globe and Mail, November 6, 2012.

Papert, S. (1996). A word for learning. In Y. Kafai \& M. Resnick (Eds.), Constructionism in practice: Designing, thinking, and learning in a digital world (pp. 9 - 24). Mahwah, NJ: Lawrence Erlbaum Associates.

Peperzak, A. T., Critchley, S., \& Bernascone R. (1996). Commentary on Levinas' "Enigma and Phenomenon". In A. T. Peperzak, S. Critchley \& R. Bernascone (Eds.), Emmanual Levinas basic philosophical writings (pp. 63-65). Indianapolis, IN: Bloomington.

Pettman, D. (2006). Love and Other Technologies: Retrofitting eros for the information age. New York, NY: Fordham University Press.

Pierce, J., Martin, D.G., \& Murphy, J.T. (2010) Relational place making: The networked politics of place. Transactions of the Institute of British Geographers, 36 (1), 54-70.

Sfard, A., \& Prusak, A. (2005). Identity that makes a difference: Substantial learning as closing the gap between actual and designated identities. In H.L. Chick \& J.L.Vincent (Eds.). Proceedings of the $29^{\text {th }}$ Conference of the International Group for the Psychology of Mathematics Education, Vol. 1, pp. 37-52. Melbourne: PME.

Smith, S. J. (2012). Caring caresses and the embodiment of good teaching. Phenomenology \& Practice, 6(2), 65-83. Available from http://phandpr.org/index.php/pandp/article/view/113/177

Sullivan, P. (2002). "It's easier to be yourself when you are invisible": Female college students discuss their online classroom experiences. Innovative Higher Education, 27(2), 129-144.

Thompson, I. (2011). Heidegger's aesthetics. Stanford Encyclopedia of Philosophy. Retrieved from http://plato.stanford.edu/entries/heidegger-aesthetics/

Tschaepe, M. D. (2003). Halo of identity: The significance of first names and naming. Janus Head, 6(1), 67-78.

Turkle, S. (1995). Life on the screen: Identity in the age of the Internet. New York, NY: Simon \& Schuster

Van Manen, M. (1997). Researching lived experience: Human science for an action sensitive pedagogy (2nd ed.). London, ON: Althouse.

Van Manen, M. (2002). Writing in the dark: Phenomenological studies in interpretive inquiry. London, ON: Althouse Press.

Van Manen, M. (2013). Phenomenology of practice and the tradition of the Utrecht School [course description]. Retrieved from http://www.summerschoolsineurope.eu/index.php?action=showcourse $\&$ id $=1882$

Van Manen, M. (2014). Phenomenology of practice: meaning-giving methods in phenomenological research and writing. Walnut Creek, CA: Left Coast Press. 
Van Manen, M., McClelland, J., \& Plihal, J. (2007). Naming student experiences and experiencing student naming. In International handbook of student experience in elementary and secondary school (pp. 85-98). Springer Netherlands.

Weber, E. T. (2008). Proper names and persons: Peirce's semiotic consideration of proper names. Transactions of the Charles S. Peirce Society: A Quarterly Journal in American Philosophy, 44(2), 346-362.

Yu, F., \& Wu, C. (2011). Different identity revelation modes in an online peer-assessment learning environment: Effects on perceptions toward assessors, classroom climate and learning activities. Computers \& Education, 57(3), 2167-2177. 